\title{
Timely Initiation and Exclusive Breastfeeding Rates at Adentan Municipality in Ghana
}

\author{
Jacob Setorglo ${ }^{1, *}$, Philip Narteh Gorleku², Bright Setorglo ${ }^{3}$, Mirabel Asomboya ${ }^{4}$, \\ Francisca Naana Arthur ${ }^{5}$, Moses K. Klevor6 \\ ${ }^{1}$ Department of Medical Biochemistry, University of Cape Coast, Cape Coast, Ghana \\ ${ }^{2}$ Department of Medical Imaging Sciences, University of Cape Coast, Ghana \\ ${ }^{3}$ Department of Nursing,Cornerstone Hospital, Texas, USA \\ ${ }^{4}$ Department of Public Health, Ensign College of Public Health, Kpong, Ghana \\ ${ }^{5}$ College of Health, Yamfo, Ghana \\ ${ }^{6}$ Department of Clinical Nutrition and Dietetics, University of Cape Coast, Ghana
}

Received November 10, 2019; Revised December 26, 2019; Accepted December 30, 2019

Copyright $\odot 2020$ by authors, all rights reserved. Authors agree that this article remains permanently open access under the terms of the Creative Commons Attribution License 4.0 International License

\begin{abstract}
Background: Early initiation of breastfeeding $(\mathrm{BF})$ has been recommended by the World Health Organization (WHO) for optimum infant growth and development. Objectives: To determine the factors associated with early initiation of $\mathrm{BF}$, exclusive breastfeeding (EBF) duration and timely introduction of complementary feeding. Methods: This was a quantitative descriptive cross-sectional design that involved 391 mothers sampled conveniently. Early initiation of BF, EBF duration, time of introduction of complementary foods and the types of complementary foods fed infants were documented. Proportions were presented for the outcome variables. Chi square and Fishers exact tests were used to evaluate the associations between the outcome variables and the independent predictor variables. Results: The mothers were aged between 15-45 years and $84 \%$ initiated BF within 30 minutes to 1 hour after delivery. Less than half $(46 \%)$ of respondents initiated complementary feeding (CF) at six months postpartum. About $40.4 \%$ fed infants formula milk during the complementary period, $32.2 \%$ fed infants locally prepared foods during the complementary period. There was a statistically significant association between gender of child $\left(\chi^{2}=2.7 ; p<0.01\right)$ and exclusive breastfeeding for six months. Maternal factors were significantly associated with knowledge level in EBF duration $\left(\chi^{2}=18.34 ; \mathrm{p}<\right.$ $0.0001)$ and time of initiation of breastfeeding $\left(\chi^{2}=22.40\right.$; $\mathrm{p}<0.0001)$. Institutional factors that showed statistical significance exclusive breastfeeding for six months were place of delivery $\left(\chi^{2}=14.60 ; p<0.001\right)$ and presence of attendant at birth $\left(\chi^{2}=14.18 ; \mathrm{p}<0.003\right)$. Conclusion: Maternal and types of health facilities that mothers visited during antenatal and where the delivered influenced BF initiation, duration and appropriate complementary
\end{abstract}

feeding practices.

Keywords Exclusive Breastfeeding, Complementary Feeding, Early Initiation of Breastfeeding, Antenatal, Adentan

\section{Introduction}

According to the United Nations Children's' Fund (UNICEF), the first 1000 days of a child's life is a crucial period for their optimal growth and development [1]. Early initiation of breastfeeding (BF) and continuous exclusive breastfeeding (EBF) are key predictors of infant survival $[1,2,3,4]$. The World Health Organization (WHO) encourages early initiation of BF within the first hour after birth; this increases the likelihood of $\mathrm{BF}$ success and generally extends BF duration $[5 ; 6]$.

The culture and tradition of BF in Ghana, has been influenced with the influx of commercially prepared foods such as formula milk. In the early 1990s, the Baby Friendly Hospital Initiative (BFHI) was put in place to shore up timely and EBF rates [3]. But this only covered women that delivered at the public health facilities and not the private ones. Mothers who delivered at home were marginalized by this policy initiative. The drawback to EBF was enhanced by increased numbers of women taking-up paid jobs in recent times compared to the early 1970s and 1980s in Ghana. Employers only allow at most three months postpartum leave before breastfeeding mothers to returned to work; this period is at variance with WHO recommendations of EBF for the first six months postpartum [5].Although global strategies have been 
developed by the WHO, UNICEF and through the Infant and Young Child Feeding (IYCF) initiatives and recommendations $[7 ; 8]$, surveys in Ghana have shown poor BF practices $[9 ; 10]$. Delayed initiation BF can lead to poor infant survival outcomes $[11 ; 12]$.

The WHO indicates that few children receive nutritionally adequate and safe complementary foods [14]. In Ghana, appropriate $\mathrm{CF}$ practices are inadequate amongst mothers $[10 ; 13]$. Despite efforts by the government to scale up $\mathrm{BF}$ and appropriate $\mathrm{CF}$ among mothers, the rates are still low [10]. It is important to assess child survival indicators in this newly created municipality to serve as a guide for planning, since Ghana's developmental planning is decentralized. This study intends to provide the micro data on early initiation of exclusive breastfeeding rates, timely initiation of exclusive breastfeeding and appropriate $\mathrm{CF}$ that are not always available but crucial for policy formulation and development for child nutrition. This study would generate data on the timing of initiation of $\mathrm{BF}$ and $\mathrm{CF}$ in an urban municipality, Adentan, which is about $20 \mathrm{~km}$ from Accra, the nation's capital.

\section{Participants and Methods}

\subsection{Study Population}

The study population was nursing mothers who attended postnatal services at the selected health facilities and lived within the study communities in the Adentan Municipality. The inclusion criterion was nursing mothers with babies between 6 and 24 months of age. Measures were put in place to ensure that primary data gathered was reliable and substantial. We performed quality control reviews of the completed questionnaires at the end of each day, to check for omissions, incomplete answers or unclear statements.

\subsection{Study Area}

The research was carried out in the Adentan Municipality of the Greater Accra Region of Ghana. The Adentan Municipality was carved out of the Tema Municipal Assembly and inaugurated in February 2008, with an estimated population of about 88,374 residents. The district lies in the savannah agro-ecological zone; and the rainfall pattern is bi-modal [15]. The Municipality is divided into four (4) sub-municipalities: Gbentaana, Sutrunaa, Koose, and NiiAshaley. The Municipality has 5 government health Centres and 17 private health facilities.

\subsection{Study Design}

This was a quantitative descriptive cross-sectional study.

\subsection{Sample and Sampling Technique}

\subsubsection{Sample Size Determination and Sampling}

The sample size was estimated using Cochran's formula $n=\frac{z^{2} p q}{e^{2}}$, where $\mathrm{n}$ denoted the sample size, $\mathrm{z}$ $=1.96$ at $95 \%$ confidence interval, e denoted a tolerated error margin of $5 \%$, p referred to the prevalence of EBF which was $52.0 \%$ [10] and $q=1-p$. The calculated sample size of 384 was increased by $10 \%$ to a total of 422 participants, in order to account for non-response and increase the precision of the estimates. Four communities and four health facilities within the Municipality were randomly selected for the study; one health facility and one community were selected from each sub-municipality,to give a total of 8 study sites. The selected health facilities were Amanfrom Health Centre, Frafraha Health Centre, Adjiringanor Health Centre and Nii Ashaley Health Centre. The communities were Ashieyie, Adentan New Village, Nanakrom and Otinshie. Purposive sampling was used to select mother and child pairs attending child welfare clinics (CWCs) at the health facilities or within households in the study communities. At the health facilities, participants that met the inclusion criterion were interviewed as they completed receiving services. Within the communities, the sampling approach was different. Firstly, a bottle was spun to determine the first direction to proceed in sampling the houses and then households. A maximum of 10 houses were sampled from each direction, after which the researchers went back to same spot to spin the bottle again for a new direction. If a direction is repeated twice, it is ignored and the bottle is spun again, until a new direction is obtained. At the community level, to reduce clustering within one area, the researchers restricted interviews to one participant per household. In situations where there were more than one qualified participant within a house or household, there was balloting between a Yes and No response written on folded pieces of paper; whoever chose Yes was interviewed and whoever chose No was excluded. 
Four communities and four health facilities within the Municipality were randomly selected

\begin{abstract}
Four communities selected; one community was selected from each submunicipality,
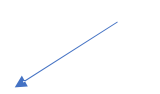

Ashieyie, Adentan New Village, Nanakrom and Otinshie.

Spun bottle for direction in each
community. 10 houses sampled. Met
inclusion criteria. One child mother
pair purposively sampled in each
household
More than one met inclusion
criteria. Ballot takes place and 'Yes'
included in the study

Four health facilities selected; one health facility from each sub-municipality

Amanfrom Health Centre, Frafraha Health Centre, Adjiringanor Health Centre and Nii Ashaley Health Centre.

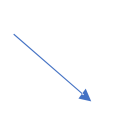

Met inclusion criterion
Child mother pair purposively sampled
after receiving care

Achieved calculated sample size $=384$

\section{Figure 1. Flow diagram of sampling procedure}

\subsection{Data Collection}

\subsubsection{Training of Research Assistants}

Four Research Assistants (RAs) who could read and write English language, as well as speak at least 2 local languages fluently (Twi and Ga languages) were recruited and trained for one day at the supervisors office. Training entailed explanation of the items in the questionnaires in English and subsequent translation into the local languages, research ethics, seeking informed consent from study participants and field data collection procedures. The training was done to ensure that the RAs collect valid and reliable data and conform to the ethical guidelines of the study.

\subsection{Tools and Techniques}

Semi-structured questionnaires were used to collect data for the study. To ensure the validity of the test instrument, the accuracy and reliability of results, the questionnaire development involved the review of sample questionnaires from related studies. Data collection involved face-to-face interviews with respondents. Data were collected in English language; however, the local languages of $\mathrm{Ga}$, Ewe and Twi were used in instances where respondents could only respond to questions in those local languages.

\subsection{Data Collection}

Data were collected by the principal investigator (PI) and four well-trained RAs who were university graduates undertaking National Service duties during the period. The PI performed quality control reviews of the completed questionnaires at the end of each day, including checks for omissions, incomplete answers or unclear statements. A total of 422 questionnaires were taken to the field; 211 were designated for the CWCs and 211 were designated for the selected communities under each sub-Municipality. A total of 391 questionnaires were completed, yielding a response rate of about $93 \%$. Approximately15 minutes was used to complete each questionnaire interview with each participant. Data were collected over a period of 3 weeks between March and April, 2017.

\section{Study Variables}

\subsection{Background Characteristics}

Information collected on the infants included their ages (months), sex, numbers in school and birth weights. Age (years), parity, ethnicity, marital status, religious affiliation, educational status, occupation and income of 
mothers were documented.

\subsection{Breastfeeding Status}

EBF awareness, time of BF initiation after delivery, introduction of breast milk substitutes before discharge from hospital, factors encouraging $\mathrm{EBF}$, factors discouraging $\mathrm{EBF}$, and experiences from past EBF were the independent variables. The early initiation of breastfeeding (EIBF) indicator was calculated according to the following WHO equation [16] :EIBF = number of children born in the last 24 months who were put to breast within an hour of birth divided by the number children born in the last 24 months, multiplied by 100 .

\subsection{Complementary Feeding Practices}

Time of CF initiation, complementary foods introduced, frequency of meals to children, nutritional status of children (from growth monitoring charts) and snacks given in-between meals were the independent variables.

\subsection{Outcome Variables}

We used EIBF as one of the outcome variables, using the recommended definition as children less than 24 months of age who were breastfed within the first hour of birth [16]. This indicator was self-reported by mothers. Other outcome variables included EBF rates and timely introduction of appropriate $\mathrm{CF}$.

\subsection{Pre-testing}

The initial questionnaire was piloted at Amasaman health Centre among 10 nursing mothers who were comparable to the sample of respondents, before the main data collection commenced. The pretesting was done to ensure that questions asked were understood and clear enough to generate relevant responses. The necessary modifications and clarification of terms were effected based on the pilot study.

\subsection{Data Handling}

Questionnaires were coded and kept under lock and key in a cupboard, and the keys were kept by the PI and one Co-PI. A soft copy of the data was stored in the Dropbox cloud storage system, and on a hard drive protected with a password known only to the PI and one co-PI.

\subsection{Data Analysis}

Epi Info (version 7) was used for data entry and data cleaning, whilst IBM SPSS (version 23) was used for data analysis. EBF awareness, BF initiation after delivery, introduction of breast milk substitutes before discharge from hospital, EBF rates, factors encouraging EBF, factors discouraging EBF and experiences from past EBF were the independent variables. $\mathrm{CF}$ initiation, complementary foods introduced, frequency of main meals to children, nutritional status of children (from growth monitoring charts) and snacks given in-between meals were the independent variables. Descriptive statistics, including frequencies and percentages were presented for background data, BF status and CF practices. Associations between EBF for six months and timely introduction of $\mathrm{CF}$ with socio-demographic factors such as sex, age, religion, education, marital status and income were analyzed using Chi square tests. A p-value of less than 0.05 was considered statistically significant.

\subsection{Ethical Considerations}

Ethical clearance (Ensign/IRB/M1) was obtained from Ensign College of Public Health. Permissions were obtained from the Health Directorate of the Adentan Municipality and the heads of the various health facilities where the surveys were conducted. The purpose of the study was fully explained to respondents, signed informed consent was obtained from each participant before the questionnaires were administered, whilst assuring participants of the confidentiality of their information. Participants had the right to opt out of the study at any time they desired, and they were made to feel comfortable and protected from any physical or mental harm in the course of the data collection. Privacy was guaranteed by holding tete-a-tete interviews with respondents in their homes. Confidentiality was further ensured by not disclosing any of the data collected on respondents deliberately or accidentally to other people.

\section{Results}

\subsection{Background Characteristics}

A total of 391 respondents were interviewed during the study period. Their age range was $17-45$ years, with two thirds of the participants aged between 25-34 years (Table 1). Regarding parity, majority $67.5 \%$ had one or two children Respondents were of different ethnicities with majority (38.6\%) being Akans. Two-thirds (77\%) of the respondents were married. About $50 \%$ of the children were aged between $12-24$ months and $51.4 \%$ of them were males. 
Table 1. Background characteristics of mothers and their children

\begin{tabular}{|c|c|}
\hline Characteristics & Number of participants $n(\%)$ \\
\hline \multicolumn{2}{|l|}{ Age of children (months) } \\
\hline $6-11$ & $195(49.9)$ \\
\hline $\begin{array}{l}12-24 \\
\text { Sex of children }\end{array}$ & $196(50.1)$ \\
\hline Males & $190(51.4)$ \\
\hline Females & $201(48.6)$ \\
\hline $\begin{array}{l}\text { Number of children attending } \\
\text { school }\end{array}$ & $81(20.7)$ \\
\hline $\begin{array}{l}\text { Normal birth weight of } \\
\text { children (above } 2.5 \mathrm{~kg} \text { ) }\end{array}$ & $382(97.7)$ \\
\hline \multicolumn{2}{|l|}{$\begin{array}{l}\text { Age categories of } \\
\text { mothers(years) }\end{array}$} \\
\hline $15-24$ & $54(13.8)$ \\
\hline $25-34$ & $264(67.5)$ \\
\hline $35-44$ & $72(18.4)$ \\
\hline $45+$ & $1(0.3)$ \\
\hline \multicolumn{2}{|l|}{ Parity } \\
\hline $1-2$ & $247(67.5)$ \\
\hline $3-4$ & $72(18.4)$ \\
\hline $5+$ & $5(1.3)$ \\
\hline \multicolumn{2}{|l|}{ Ethnicity } \\
\hline Ga/Adagme & $50(12.8)$ \\
\hline Akan & $151(38.6)$ \\
\hline Ewe & $95(24.30$ \\
\hline Krobo & $25(6.4)$ \\
\hline Dagomba & $64(16.4)$ \\
\hline Others & $6(1.5)$ \\
\hline \multicolumn{2}{|l|}{ Marital status } \\
\hline Married & $301(77.5)$ \\
\hline Co-habiting & $25(6.2)$ \\
\hline Divorced/separated & $7(1.8)$ \\
\hline Single & $56(14.3)$ \\
\hline Widowed & $2(0.5)$ \\
\hline
\end{tabular}

Background Characteristics of Respondents Continued

Majority $(82.9 \%)$ of the respondents were Christians. About $7 \%$ of the participants had tertiary education; and majority $(46.0 \%)$ earned a monthly income of GHS 500 (USD 100.00) and below. About half (50.4\%) of the respondents were self-employed (mostly petty traders, hairdressers, and seamstresses). While 5.6\% have never attended school, $12.3 \%$ received 6 years of formal education while majority $31.2 \%$ are graduates from vocational institutions. About 50.4\% were self-employed while $21.2 \%$ were unemployed. Regarding income status, $46.0 \%$ earned less than GHф500 a month which equivalent to about USD 100.

Table 2. Background characteristics of respondents

\begin{tabular}{|c|c|}
\hline Characteristics & $\mathrm{n}(\%)$ \\
\hline \multicolumn{2}{|l|}{ Religious affiliation } \\
\hline Christian & $324(82.9)$ \\
\hline Muslim & $58(14.8)$ \\
\hline Traditional & $9(2.3)$ \\
\hline \multicolumn{2}{|l|}{ Educational status } \\
\hline Never been to school & $22(5.6)$ \\
\hline Primary & $48(12.3)$ \\
\hline JHS & $97(24.8)$ \\
\hline Secondary & $73(18.7)$ \\
\hline Vocational & $122(31.2)$ \\
\hline Tertiary & $29(7.4)$ \\
\hline \multicolumn{2}{|l|}{ Employment status } \\
\hline Government institution & $49(12.5)$ \\
\hline Private institution & $62(15.9)$ \\
\hline Self-employed & $197(50.4)$ \\
\hline Unemployed & $83(21.2)$ \\
\hline \multicolumn{2}{|l|}{ Income status } \\
\hline No response ${ }^{\%}$ & $67(17.1)$ \\
\hline$<\mathrm{GH} \notin 500$ & $180(46.0)$ \\
\hline Between GH $\varnothing 500-\mathrm{GH} \phi 1000$ & $81(20.7)$ \\
\hline Between GH $\varnothing 1000-$ GH $\varnothing 2000$ & $51(13.0)$ \\
\hline Above GH $\not 2000$ & $12(3.2)$ \\
\hline
\end{tabular}

$\%=$ refused to give response for fear of taxation * Equivalence of 1 USD to 1 Ghana Cedi $=5.0$ Ghana Cedis 
Table 3. Breastfeeding status of mothers with children 6-24 months old

\begin{tabular}{|c|c|}
\hline Variables & $\mathrm{n}(\%)$ \\
\hline Exclusive breastfeeding awareness & $361(92.3)$ \\
\hline \multicolumn{2}{|l|}{ Breast initiation after delivery } \\
\hline Within 30 minutes & $232(59.3)$ \\
\hline Within 1 hour & $43(11.0)$ \\
\hline More than 1 hour & $98(25.1)$ \\
\hline Others ( 24 hours and above) & $14(4.6)$ \\
\hline $\begin{array}{l}\text { Introduction of breast milk substitutes before } \\
\text { discharge from hospital }\end{array}$ & $67(17.1)$ \\
\hline $\begin{array}{l}\text { EBF duration } \\
\text { Up to3 months and below }\end{array}$ & $78(20.1)$ \\
\hline 4-5 months & $83(21.1)$ \\
\hline 6 months & $230(58.8)$ \\
\hline Mothers still breastfeeding & $337(86.8)$ \\
\hline \multicolumn{2}{|l|}{ Factors encouraging EBF } \\
\hline Employer support & $11(2.8)$ \\
\hline Family and friends support & $89(22.7)$ \\
\hline Health worker support & $119(30.4)$ \\
\hline \multicolumn{2}{|l|}{ Factors discouraging EBF } \\
\hline Less flow of breast milk & $40(10.2)$ \\
\hline Return to work after maternity leave & $27(6.7)$ \\
\hline Did not see it necessary & $26(6.6)$ \\
\hline \multicolumn{2}{|l|}{ Experiences from past EBF } \\
\hline Baby gains weight and hardly falls sick & $140(35.8)$ \\
\hline Economically friendly to family & $49(12.5)$ \\
\hline Very demanding & $22(5.6)$ \\
\hline Served as form of family planning & $18(4.6)$ \\
\hline No experience & $9(2.3)$ \\
\hline
\end{tabular}

\subsection{Exclusive Breastfeeding Practices}

EBF practices of mothers are presented in Table 3. Majority (80.0\%) of mothers initiated BF within the first hour after birth. About $17 \%$ gave infant formula after delivery. More than half (58.8\%) of mothers exclusively breastfed their children for 6 months. Health worker support $(30.4 \%)$ was found to be the most encouraging factor in EBF practice while less flow of breast milk $(10.2 \%)$ was found to be the most discouraging factor in practicing EBF. Based on their past experiences with EBF, more than a third of respondents $(35.8 \%)$ noted their babies gained weight and hardly fell sick.

\subsection{Complementary Feeding Practices amongst Mothers with Children 6-24 Months Old}

A high proportion (45.5\%) of mothers introduced $\mathrm{CF}$ at 6 months of age, while at least 15\% introduced CF between 7 and 8 months of age (Table 4). Regarding type of complementary foods introduced, $40 \%$ of mothers fed infant formula and about a fifth introduced their children to local home prepared foods and plain maize porridge. Most respondents (45.0\%) added fruits and vegetables to their children's meals, with about a quarter of them adding fruits and vegetables at least once every day to children meals. About three-quarters $(72.1 \%)$ of mothers fed their wards between 3-4 times a day, and majority (70.3\%) of them added at least one snack a day to main meals. Majority $(87.0 \%)$ of the children were birthed with normal weights.

Table 4. Complementary feeding practices amongst mothers with children 6-24 months old

\begin{tabular}{|l|l|}
\hline Feeding practices & $\begin{array}{l}\text { No of Participants } \\
\mathrm{n}(\%)\end{array}$ \\
\hline Complementary feeding initiation & \\
\hline At 6 months & $178(45.5)$ \\
\hline Between 7 -8 months & $60(15.3)$ \\
\hline Less than 6 months & $153(39.2)$ \\
\hline Complementary foods introduced & \\
\hline Formula & $158(40.4)$ \\
\hline Fortified porridge & $22(5.6)$ \\
\hline Local, home prepared foods & $126(32.2)$ \\
\hline Plain koko (corn dough porridge) & $85(21.7)$ \\
\hline Fruits and vegetables fed to children & $352(90)$ \\
\hline Frequency of fruits and vegetable intake & \\
\hline Every day (at least one serving a day) & $100(25.6)$ \\
\hline Often times (at least 2 to 3 days intervals) & $179(45)$ \\
\hline Once a while (1 to 2 weeks intervals) & $76(9.6)$ \\
\hline Not at all & $36(9.2)$ \\
\hline Frequency of main meals to children & \\
\hline 2 times & $37(9.5)$ \\
\hline 3-4 times & $287(72.1)$ \\
\hline 5 times and more & $62(15.9)$ \\
\hline Not yet & $10(2.6)$ \\
\hline $\begin{array}{l}\text { Nutritional status of children (from growth } \\
\text { monitoring charts) }\end{array}$ \\
\hline Normal & $340(87.0)$ \\
\hline Moderately underweight & $45(11.5)$ \\
\hline Severely underweight & $4(1.0)$ \\
\hline Overweight & $2(0.5)$ \\
\hline Snacks given in-between meals & $63(16.1)$ \\
\hline At least one snack a day & $53(13.5)$ \\
\hline Sometimes (not every day) & \\
\hline Not given & \\
\hline
\end{tabular}


Table 5. Chi-square tests of associations of EBF and timely introduction of appropriate CF and independent variables

\begin{tabular}{|c|c|c|c|c|}
\hline \multirow{2}{*}{ Independent variables } & \multicolumn{2}{|c|}{ Exclusive breastfeeding for six months } & \multicolumn{2}{|c|}{ Timely introduction of complementary feeding } \\
\hline & $\chi^{2}$ & $\mathrm{p}$ - value & $\chi^{2}$ & p-value \\
\hline Sex of child & 2.7 & $0.01 *$ & 0.66 & 0.72 \\
\hline Marital status & 3.192 & 0.53 & 11.62 & 0.17 \\
\hline Mothers education & 2.807 & 0.73 & 14.15 & 0.17 \\
\hline Occupation & 2.69 & 0.61 & 6.47 & 0.60 \\
\hline Parity & 6.05 & 0.11 & 8.79 & 0.19 \\
\hline Income status & 6.7 & 0.244 & 11.36 & 0.33 \\
\hline Mother's age & 31.97 & 0.23 & 48.13 & 0.82 \\
\hline ANC visits & 9.95 & $0.003^{*}$ & 1.13 & 0.57 \\
\hline Knowledge level in EBF & 18.34 & $<0.0001 * *$ & 2.87 & 0.49 \\
\hline Place of delivery & 14.6 & $<0.001 * *$ & 2.96 & 0.58 \\
\hline Attendance at birth & 14.18 & $0.003 *$ & $5 . .47$ & 0.49 \\
\hline Time of breastfeeding initiation & 22.4 & $<0.0001 * *$ & 6.65 & 0.58 \\
\hline Postnatal attendance & 4.72 & 0.094 & 0.47 & 0.06 \\
\hline
\end{tabular}

*Statistically significant at $\mathrm{p}<0.05$; ** statistically significant at $\mathrm{P}<0.001$; Chi square tests

\subsection{Chi-square Tests of Associations for EBF and Timely Introduction of Appropriate Complementary Feeding against Independent Variables}

Chi-square tests of association between EBF for 6 months and timely introduction of CF at 6 months (Table $5)$ and independent variables, showed that sex of child $\left(\chi^{2}\right.$ $=2.7 ; \quad \mathrm{P}=0.01) ; \quad$ ANC visits $\quad\left(\chi^{2}=9.95 ; \quad \mathrm{P}=0.003\right)$; knowledge level in $\mathrm{EBF}\left(\chi^{2}=18.34 ; \mathrm{P}<0.0001\right)$; place of delivery $\left(\chi^{2}=14.6 ; \mathrm{P}<0.001\right)$; attendance at birth $\left(\chi^{2}\right.$ $=14.18 ; \mathrm{P}=0.003)$; and time of $\mathrm{BF}$ initiation $\left(\chi^{2}=22.4 ; \mathrm{P}<\right.$ $0.0001)$ were significantly associated with $\mathrm{EBF}$ for 6 months (Table 4).Independent variables that were significantly associated with EBF also had a positive association. However, none of the independent variables had any significant association with timely introduction of $\mathrm{CF}$ at 6 months of child's age.

\section{Discussion}

EBF is vital for child development and improves immunity. This study focused on the timely initiation of $\mathrm{BF}, \mathrm{BF}$ status and the timely of initiation of $\mathrm{CF}$ by mothers in the Adentan Municipality. We found the prevalence of EBF for the first 6 months of life (59\%)in our study compared well with national averages of $63 \%$ in the 2008 and $52 \%$ in the 2015 [9;10]. The observed result in this study corroborates results from a hospital study elsewhere [17]. Early initiation of BF, noted as BF baby within one hour of birth, among mothers in our study was very good, based on the WHO classification of $50-89 \%$ [1]. Our finding is higher than that reported by World Breastfeeding Trend Initiative $[19 ; 20]$. This is likely due to the fact that mothers had support during delivery and their knowledge in EBF was significant, probably due to the education received during the frequent antenatal visits (Table 4).

Mothers who initiated BF successfully were likely to continue with EBF because their knowledge levels were high (Table 4). This finding corroborates that of [21]. The role of healthcare professionals can be very critical in providing knowledge and support for breastfeeding when deliveries occur at health facilities [22] and this was shown by the statistically significant associations with presence of attendance at birth and place of delivery.

Higher proportions of mothers introduced complementary foods after six months as recommended by WHO; a high proportion also introduced formula feeds. Less than half of the mothers introduced complementary foods timely, and this may be due to mothers not noticing the growth faltering of their children since majority of 
children appeared to have normal nutritional status according to their growth monitoring cards (Table 4), and a lack of support at home to prepare local nutrient dense foods for infants. It has been reported that when support is lacking mothers are unable to implement $\mathrm{BF}$ and $\mathrm{CF}$ knowledge (Adjei and Schubert, 2003).

Although majority of mothers gave between 3-4 servings of main meals and added at least 1-2 snacks a day in addition to breast milk, only a quarter of them added fruits and vegetables to baby meals daily. Poor complementary feeding practices are problems in infant feeding in Ghana $[9 ; 10]$. Cultural and beliefs systems are sometimes associated with the finding [23;24].

The study has few limitations. Due to the nature of schedules of the CWCs, participants were not randomly selected due to limited number of mothers coming in at a particular time, because they had different appointments times, which was once within every month. The strength of the study lies in the fact that it determined the factors that were associated with infant feeding in a disaggregated manner.

\section{Conclusions}

Less than half of mothers practiced EBF. Timely and appropriate introduction of $\mathrm{CF}$ was highest at six months, although half of respondents initiated $\mathrm{CF}$ at 6 months postpartum. The consumption of fruits and vegetables by infants was generally low. Maternal and health facility factors do play roles in $\mathrm{BF}$ initiation and duration. Advocacy regarding the importance of EBF should be strengthened to improve on the current child feeding practices.

\section{Abbreviations}

\author{
BF: Breast feeding \\ EBF: Exclusive Breastfeeding \\ BFHI: Baby Friendly Hospital Initiative \\ CF: Complementary Feeding \\ Co-PI: Co-Principal Investigator \\ CWC: Child Welfare Clinic \\ IYCF: Infant and Young Child Feeding \\ PI: Principal Investigator \\ USD: United States Dollar \\ WHO: World Health Organization
}

\section{Acknowledgments}

We the authors thank the children and mothers/caretakers at Manya Krobo for participating in this study. We are grateful to the Municipal Assembly for allowing us to do this study and for their support.

\section{Funding}

All activities that led to the writing of this manuscript were self-financed.

\section{Availability of Data}

All data supporting the conclusions of this article are in the manuscript.

\section{Authors' Contributions}

JS was engaged in data collection, analysis and interpretation of data, drafting and reviewing of manuscript. MKK was involved in samples and data collection, data analysis and interpretation of data, reviewing of the manuscript. PNG was involved in data management, data analysis, drafting and reviewing of manuscript. GE was engaged in sample collection, data analysis as well as drafting and reviewing of manuscript. FNA was involved in data analysis, drafting and reviewing of manuscript. BS was involved in data interpretation and reviewing of manuscript. All authors approved of final version of the manuscript.

\section{Ethical Approval and Consent to Participate}

Ethical approval was given by Institutional Review Board of Ensign College of Public Health. Study participants gave their written consents or thumb impression to participate. Permission was granted by the Municipal Assembly.

\section{Competing Interest}

Authors have no conflict of interest.

\section{REFERENCES}

[1] United Nations Children's Fund (UNICEF). World Health Organization. Capture the moment, early initiation of breastfeeding: The best start for every newborn. New York: UNICEF; 2018.

[2] Victora, C. G., Bahl, R., Barros, A. J., França, G. V., Horton, S., Krasevec, J., ... \& Group, T. L. B. S. (2016). Breastfeeding in the 21st century: epidemiology, mechanisms, and lifelong effect. The Lancet, 387(10017), 475-490.

[3] Biks GA, Berhane Y, Worku A, Gete YK. Exclusive breast feeding is the strongest predictor of infant survival in 
Northwest Ethiopia: a longitudinal study. J Health Popul Nutr. 2015; 34: 9.

[4] Awasthi, A., \& Awasthi, S. (2016). Promoting exclusive breastfeeding in India to reduce neonatal mortality. Clinical Epidemiology and Global Health, 4(4), 151-152.

[5] World Health Organization. Infant and young child feeding a tool for assessing national practices, policies and programmes. Geneva; 2003. Available at http://www.who.i

nt/nutrition/publications/inf_assess_nnpp

eng.pdf. Accessed 4 June 2018.Accessed 4 June 2018.

[6] World Health Organization. Early initiation of breastfeeding to promote exclusive breastfeeding. 2018. Available at http://www.who.int/elena/titles/ early_breastfeeding/en/. Accessed 4 June 2018.Accessed 4 June 2018 .

[7] Ogbeide, D. O., Siddiqui, S., Al Khalifa, I. M., \& Karim, A. (2004). Breast feeding in a saudi arabian community. Saudi Med J, 25(5), 580-584.

[8] Al-Jawaldeh A, Abul-Fadl A. Assessment of the baby friendly hospital initiative implementation in the eastern Mediterranean region. Children. 2018; 5(3):41. 8. Alzaheb R. A review of the factors associated with the timely initiation of breastfeeding and exclusive breastfeeding in the Middle East. Clin Med Insights: Pediatr. 2017; 11: $1-15$.

[9] Ghana Statistical Service (GSS), Ghana Health Service (GHS), and ICF Macro. 2009. Ghana Demographic and Health Survey 2008. Accra, Ghana: GSS, GHS, and ICF Macro.

[10] Ghana Statistical Service (GSS), Ghana Health Service (GHS), and ICF Macro. 15. Ghana Demographic and Health Survey 2014. Accra, Ghana: GSS, GHS, and ICF Macro.

[11] Smith, E. R., Hurt, L., Chowdhury, R., Sinha, B., Fawzi, W., Edmond, K. M., \& Neovita Study Group. (2017). Delayed breastfeeding initiation and infant survival: A systematic review and meta-analysis. PLoS One, 12(7), e0180722.

[12] Khan, J., Vesel, L., Bahl, R., \& Martines, J. C. (2015). Timing of breastfeeding initiation and exclusivity of breastfeeding during the first month of life: effects on neonatal mortality and morbidity - a systematic review and meta-analysis. Maternal and child health journal, 19(3), 468-479.

[13] Nutrition country profile of Ghana. Ministry of Health (2009).

Available:http://www.moh.gov.gh/wp-content/uploads/20 16/02/Nutrition-Country-Profile-Ghana.pdf. Accessed: 19th September, 2019

[14] World Health Organization. (2015). Climate and health country profile 2015: Ghana (No.WHO/FWC/PHE/EPE/15.08).

[15] MHD Lower Manya Krobo Municipal Assembly, (2014). Lower manya krobo municipality. , p.189.

[16] World Health Organization (WHO). Baby-friendly hospital initiative: revised, updated and expanded for integrated care. Strengthening and sustaining the baby-friendly hospital initiative: a course for decision-makers. Geneva: WHO; 2009. [online] Available at:http://www.who.int/nutrition/publications/infantfeeding/ bfhi_trainingcourse/en/[Accessed 7 Dec 2018]

[17] Ford, K., \& Labbok, M. (1990). Who is breast-feeding? Implications of associated social and biomedical variables for research on the consequences of method of infant feeding. The American journal of clinical nutrition, 52(3), 451-456.

[18] World Health Organization (WHO). Indicators for assessing infant and young child feeding practices. Part I: definitions. Conclusions of a consensus meeting held 6-8. November 2007 in Washington D.C., USA. Geneva: WHO; 2008.

[19] El-Gilany A, Shady E, Helal R. Exclusive breastfeeding in Al-Hassa, Saudi Arabia. Breastfeed Med. 2011; 6(4):209-13.

[20] The World Breastfeeding Trends Initiative (WBTi). Kingdom of Saudi Arabia report.http://worldbreastfeedingtrends.org/GenerateReport s/report/WBTi-Saudi-Arabia-2016.pdf

[21] Cherop, C., Keverenge-Ettyang, A., \& Mbagaya, G. M. (2009). Barriers to exclusive breastfeeding among infants aged 0-6 months in Eldoret municipality, Kenya. East African journal of public health, 6(1).

[22] Adjei, E., \& Schubert, J. (2003). Follow-up survey III: A rapid appraisal of breastfeeding and complementary feeding knowledge and practices in Ghana. Linkages/Academy for Educational Development. Processed.

[23] Adhikari R (2010) Food Utilization Practices, Beliefs and Taboos in Nepal: An Overview. Washington, DC: Global Health Technical Assistance Project, USAID.

[24] Eljack, I. A., \& Niel, A. R. A. A. H. (2015). Child health indicators in Shareq Elneel locality, Khartoum State, Sudan: a cross-sectional study. International Journal of Child Health and Nutrition, 4(2), 67-77. 